\title{
Interaction of nanofillers in injection-molded graphene/carbon nanotube reinforced PA66 hybrid nanocomposites
}

Doagou-Rad, Saeed; Islam, Aminul; Jensen, Jakob S.; Alnasser, Ammar

Published in:

Journal of Polymer Engineering

Link to article, DOI:

10.1515/polyeng-2018-0060

Publication date:

2018

Document Version

Peer reviewed version

Link back to DTU Orbit

Citation (APA):

Doagou-Rad, S., Islam, A., Jensen, J. S., \& Alnasser, A. (2018). Interaction of nanofillers in injection-molded graphene/carbon nanotube reinforced PA66 hybrid nanocomposites. Journal of Polymer Engineering, 38(10), 971-981. https://doi.org/10.1515/polyeng-2018-0060

\section{General rights}

Copyright and moral rights for the publications made accessible in the public portal are retained by the authors and/or other copyright owners and it is a condition of accessing publications that users recognise and abide by the legal requirements associated with these rights.

- Users may download and print one copy of any publication from the public portal for the purpose of private study or research.

- You may not further distribute the material or use it for any profit-making activity or commercial gain

- You may freely distribute the URL identifying the publication in the public portal 


\title{
Interaction of the nanofillers in the Injection molded Graphene/Carbon nanotube reinforced PA66 hybrid nanocomposites
}

\author{
Saeed Doagou-Rad ${ }^{\mathrm{a}, \mathrm{b}, *}$, Aminul Islamª, Jakob Søndergaard \\ Jensen $^{\mathrm{a}}$, Ammar Alnasser ${ }^{\mathrm{b}}$ \\ ${ }^{a}$ Centre for Acoustic-Mechanical Microsystems (CAMM),
} Technical University of Denmark, Building 352, DK-2800 Kgs. Lyngby, Denmark

${ }^{b}$ Department of Mechanical Engineering, Technical University of Denmark, Produktionstorvet, Building 427A, DK-2800 Kgs. Lyngby, Denmark

* Corresponding author. Tel.: +45-4525-4867; fax: +45-4525-4700. E-mail address: sadora@mek.dtu.dk

ORCID ID: 0000-0002-0935-3190

\begin{abstract}
Interaction of Multi Walled Carbon Nanotubes (MWCNT) and Graphene NanoPlatelets (GNP) within injection molded thermoplastic based nanocomposites is investigated. The research shows how the nanofillers combination ratio and content influence the properties in the semicrystalline thermoplastic based composites. Three main groups of Polyamide (PA 6,6) based composite specimens containing either or both of the nanofillers are prepared. Results show that the single inclusion of the nanomaterials improves the mechanical and thermal properties significantly. However, the combined incorporation of both nanofillers in the polymeric matrix does not lead to the linear combination of the observed behaviors. While the mechanical properties and the degrees of crystallinity improve, the thermal conductivities decrease in the hybrid composites for similar nanofiller contents. Rheological and crystallization investigations also showed the dominant
\end{abstract}


influence of the nanotubes in the structure of the hybrid composites. The underlying mechanisms of modulation in the properties were also investigated in detail.

Keywords: Nanocomposites; Injection moulding; Crystallization; Mechanical properties; Thermal properties; Rheology

\section{Introduction}

Novel nanomaterials and their comprising composites have introduced new functionalities for different applications. Carbon nanotubes (CNTs) and Graphene NanoPlatelets (GNPs) present a variety of outstanding properties including very high stiffness (Elastic modulus $\sim 1 \mathrm{TPa})$, electrical $(\sim 0.1 \mu \Omega \mathrm{cm})$, and thermal $(\sim 6000 \mathrm{~W} / \mathrm{mK})$ conductivities, etc. Therefore, they are being developed and utilized for many novel applications [1-5].The acquired multifunctional characteristics from nanocomposites have led to novel possibilities for different industrial sectors. However, the stable and optimized production of polymeric nanocomposite components is challenging.

In order to exploit the advantages of these nanofillers in many applications, they should be effectively incorporated within a polymeric matrix. In fact, attaining proper deagglomeration and dispersion within the polymeric matrix is crucial to reach the desired properties of the nanocomposites [6]. Reaching an acceptable state of dispersion in the composites reinforced with the CNTs and/or GNPs can be a challenging task due to their high interfacial energy [7]. Due to their nanoscale dimensions and high aspect ratios, the attractive forces arising from Van der Waals and $\pi-\pi$ interactions make de-agglomeration difficult. Although, mixing methods like solution mixing have shown promising results in attaining proper dispersion states, they present some major drawbacks. The need of large amounts of solvents, poor solubility of many polymers in the currently used solvents, and damaging nanofillers in addition to environmental issues make solution mixing not the preferable approach especially at industrial scales. In comparison, melt mixing provides several advantages such as creating considerably less pollutant residuals, mass production, high speed, and lower costs, which makes it favored especially in many industrial sectors. This process involves melting of the selected polymer at high temperatures and mixing it with the defined amount of nano additives through rotational and shear forces to reach the desirable content of the nanofillers within the composite. However, the quality of the products depends on parameters such as polymer characteristics, compatibility of the nanofiller and matrix, interface behavior, etc. [8]. Additionally, combination of different fillers inside the microstructure of the nanocomposites have been considered to improve 
the properties in the hybrid composites [8-10]. Hybridization involves combination of two or more fillers with different scale, geometry, and characteristics in the desired matrix to benefit from the advantages of all of the included fillers in the new material. This process could lead to novel behaviors and improvements that were not found in the composites reinforced by the either of the fillers. Combination of different fillers such as $\mathrm{Au}$ nanoparticles, nano-sized silicon carbide, Graphite Nanoplatelets, $\mathrm{MnO}_{2}$ nano-spheres, boron nitride, carbon black, etc. with carbon nanotubes within polymeric structures have shown promising enhancements in the behavior of the produced hybrid nano composites [12]-[16].

Several studies have investigated the synergic effects of carbon nanotubes and Graphene nanofillers [10], [17]-[19]. While the nature of the introduced synergic effect is not completely known, it is speculated that the simultaneous presence of the two nanofillers can help homogenizing the whole microstructure through interfering in the attractive interfacial forces leading to enhanced interfaces. The presence of the two nanofillers can lead to the formation of a co-supporting network where the carbon nanotubes act as bridges between the graphene nanofillers [20]. However, the results and mechanisms depend on the chosen polymeric matrix, processing method, characteristics of the nanofillers, and the considered contents. While these noble nanofillers become more industrially and economically viable for the different multifunctional purposes, a detailed study on the feasibility of their processing via established manufacturing methods seems necessary. The potential multifunctional improvements arising from a stable production of hybrid nanocomposites based on industrially favorable engineering polymers as matrix could facilitate their applications in many products.

The purpose of this study is to investigate the influence of the combination of two nanofillers on the properties of semicrystalline polymeric based composites. The investigation targets to find the optimal content and combination of nanofillers for the thermal and mechanical properties. The considered methods of production are consecutive melt mixing and injection molding, which are industrially favorable methods. The influence of the content and combination ratio of the nanofillers on the different properties of the nano and hybrid composites such as rheological, mechanical, thermal, and crystallization behaviors were investigated. Scanning and transmission electron microscopy techniques were also used to study the dispersion states and arrangement of the nanofillers within the matrix. The performed investigations were used to unveil the underlying modulation mechanisms for the observed properties and trends. 


\section{Experimental Section}

\subsection{Materials}

The MWCNTs used in this study are catalytic chemical vapor deposition produced thin MWCNTs (NC $7000^{\mathrm{TM}}$ ) by Nanocyl SA, Belgium, with the average aspect ratio of 67 $\left(\mathrm{d}_{\mathrm{ave}}=10.4 \mathrm{~nm}\right)$ [21]. The Graphene NanoPlatelets (thickness $\left.=2-5 \mathrm{~nm}\right)$ with the average surface area of $500 \mathrm{~m}^{2} / \mathrm{g}$, and the size range of $100 \mathrm{~nm}$ to $1 \mu \mathrm{m}\left(\mathrm{XGNP}^{\circledR}\right)$ were acquired from XGSciences, USA in an initially agglomerated state. In Fig. 1 TEM micrographs are showing the used carbon nanotubes (Fig. 1(a)), and Graphene NanoPlatelets (Fig. 1(b)). Both nanofillers are commercially available, and are viable for industrial applications. As matrix material a Polyamide or Nylon (PA 6,6) from ALBIS Plastic GmbH, Germany ( $T_{\mathrm{g}}$ $=54.8^{\circ} \mathrm{C}, \mathrm{T}_{\mathrm{m}}=262.9^{\circ} \mathrm{C}$ ) was used.
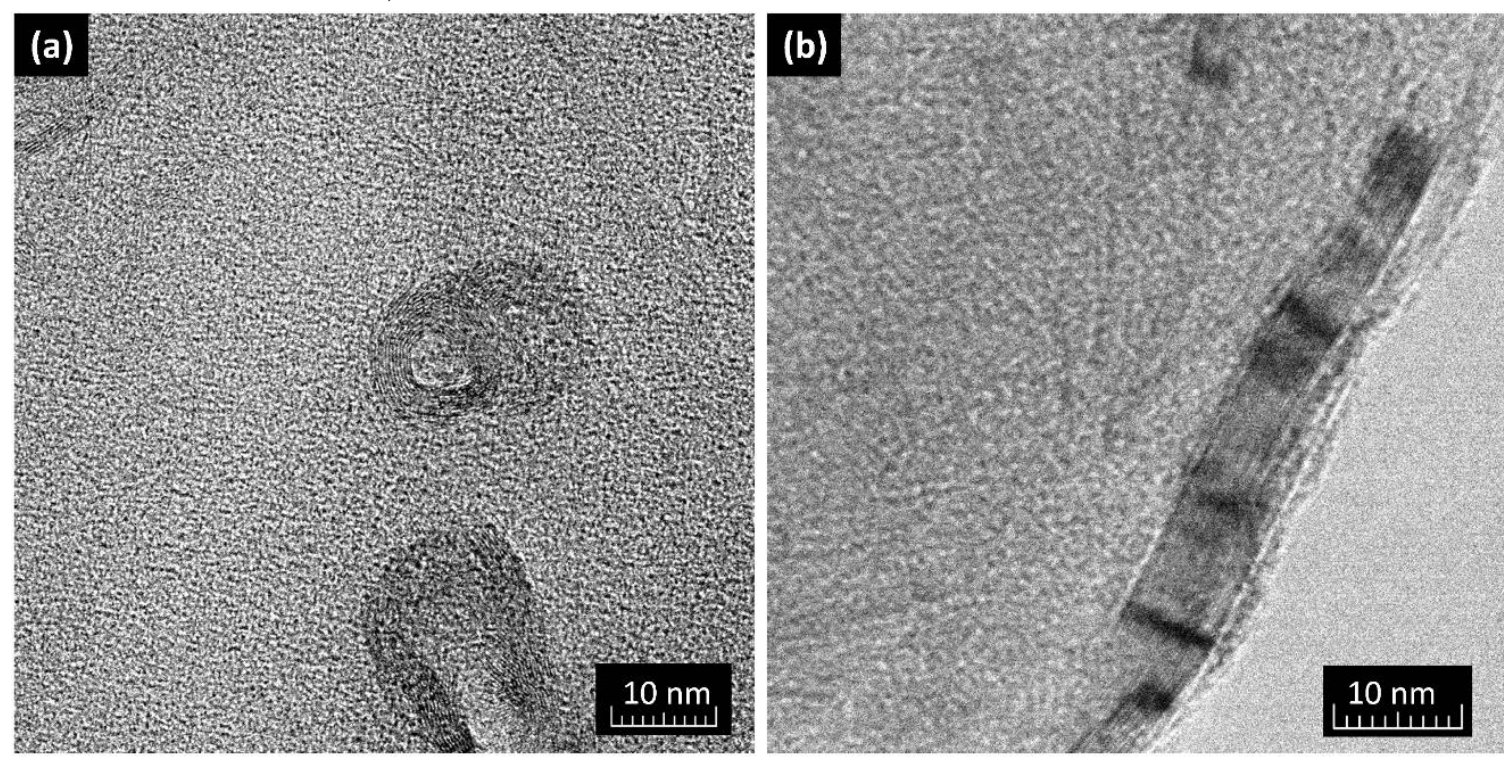

Fig. 1 TEM micrographs of the used nanofillers (a) multiwalled carbon nanotubes, and (b) multi-layer graphenes.

\subsection{Melt mixing and injection molding}

To perform the melt mixing process a conical counter rotating twin-screw extruder (HAAKE $^{\mathrm{TM}}$ Rheomex CTW, $\Phi=31.8 / 20 \mathrm{~mm}$ rear/front, $\mathrm{L}=300 \mathrm{~mm}$ ) was selected. PA 6,6 based masterbatches filled with $15.0 \mathrm{wt}$ \% of the aforementioned MWCNTs, and $12.0 \mathrm{wt}$. 
$\%$ of the GNPs were prepared initially to be used in the dilution process. Prior to feeding the materials to the extruder, the neat polymer and masterbatches were dried, weighted, and hand-mixed in sealed bags. Two series of PA 6,6 based nanocomposites with the different contents of 1.0, 3.0, 5.0, and 6.0 wt. \% of either MWCNTs or GNPs were produced. In addition, hybrid nanocomposites comprising different ratios of MWCNTs and Graphene NanoPlatelets were produced. The ratios of MWCNTs to GNPs within the polymeric composition of the hybrid nanocomposites were 1.0/2.0, 2.0/1.0, and 3.0/3.0 wt. $\%$. During the blending process in the twin screw extruder, the temperature distribution was kept from 265 to $280{ }^{\circ} \mathrm{C}$ (feed section to die), with the average temperature of $275^{\circ} \mathrm{C}$.

The specific geometry of carbon nanotubes and graphene with their small size and high aspect ratios (orders of several micrometers over several nanometers) acutely deter acquiring an acceptable dispersion state, where the polymeric matrix can benefit from the inclusion of the nanofillers effectively. In fact, strong Van der Waals (VdW) attractive forces along with the frictional forces arising from entanglement between the nanofillers themselves make reaching to desired dispersion states challenging. The VdW forces are proportional to the inverse of the radius of particles [22]. Therefore, the small size of the fillers magnify these weak forces significantly. The relation between the VdW forces and the gravitational forces is described by the adherence ratio [23]:

$$
\frac{F_{V d W}}{F_{G}}=\frac{C_{H}}{4 \pi \rho_{s} g a^{2} R^{2}}
$$

where, $F_{V d W}$ and $F_{G}$ are Van der Waals and gravitational forces, respectively, $C_{H}$ is the Hamaker constant [22], $\rho_{s}$ solid density of particles, $R$ radius of particles, and $a$ is the contact distance. Specifically, for particles with the average diameters of $10 \mathrm{~nm}-1.0 \mu \mathrm{m}$, the Van der Waals attraction forces are $10^{8}-10^{4}$ times stronger than the gravitational forces.

In order to break up the nano additive agglomerates and reach their effective size, the external stress acting on the agglomerates should exceed the bonding strength of the aggregates [24]:

$$
\sigma_{\text {agg }}=1.1 \frac{(1-\varepsilon)}{\varepsilon} \times \frac{F_{\text {sum }}}{d_{n}^{2}}
$$

where $\varepsilon$ is the porosity of the aggregate clusters, $F_{\text {sum }}$ is the force between the nano particles within the cluster, and $d_{n}$ is the representative diameter of the nano additives. It 
should be noted that $F_{\text {sum }}$ is the summation of the counteracting Van der Waals attractive and electrostatic repulsive forces.

In fact, in order to break the agglomerates and reach a homogeneous dispersion, shear forces arising from screws in either twin-screw extruder or the injection molding machine, should overcome the agglomerate strength. Wetting is the first step in the de-agglomeration process. In other words, polymer molecules in the melt state should be able to grasp and maintain their contact to the nanofillers. The wetting process depends mainly on the polymer characteristics and its polarity. Following the wetting step, if the shear stress in the melt is larger than the agglomerate strength ( $\sigma_{\text {agg }}$ ), a dispersion process through either rupture or erosion initiates. Assuming perfect wetting, the applied shear stress on the agglomerates can be written in the form of [25]:

$$
\tau_{\text {ext }}=k \eta \dot{\gamma}
$$

where, $\eta$ is the matrix viscosity, $\dot{\gamma}$ is the shear rate, and $k$ is a coefficient dependent on the flow field and agglomeration geometry characteristics.

Injection molding of the nanocomposite specimens was performed on a Ferromatik, Milacron, USA following the instructions of ISO 294-1. The geometry of the cavity of the mold was dog-bone shape which was designed based on ISO 527-2 2012. At each batch after reaching stability, 35 samples were acquired and stored in vacuum bags. Constant cooling time of $10 \mathrm{~s}$ was applied for all the experiments.

\subsection{Characterization}

In order to characterize the mechanical properties of the injection-molded specimens, uniaxial tensile experiments were conducted using a MTS 858, USA according to ISO 5271 2012. From each series of specimens produced via the defined setting and content, 10 samples were selected randomly, and tested in the dry as molded state.

The material hardness was measured in the form of Vickers hardness using a microhardness test instrument (FM 700, FUTURE-TECH, Japan) based on the instructions of ISO 6507. The indenting loads of $2.0 \mathrm{~N}$ were applied on 10 indent regions on the dogbone specimens. Experiments were conducted on at least three different specimens with similar filler content.

The thermal conductivity experiments were conducted on compression molded cylindrical specimens (diameter $=60 \mathrm{~mm}$, thickness $=10 \mathrm{~mm}$ ) using an ISOMET 2104 (Applied Precision Ltd., Slovakia) device. The measurement was based on analysis of the temperature response of the analyzed material to heat flow impulses. The heat flow was 
excited by electrical heating of resistor heater inserted into the circular surface probe which is in direct heat contact with the specimens.

Differential scanning calorimetry (DSC) experiments were conducted on a Discovery DSC (TA Instruments, USA) under Nitrogen atmosphere. A sample of 4-6 mg of the nanocomposites was cut from the middle section of the injection molded specimens, and measured in sealed aluminum pans. DSC experiments were performed in the temperature range of $-90{ }^{\circ} \mathrm{C}$ to $310{ }^{\circ} \mathrm{C}$ with $10{ }^{\circ} \mathrm{C} / \mathrm{min}$ heating and cooling rates. The degree of crystallinity was also determined from the second heating, and the enthalpy of fusion in $100 \%$ crystalline PA 6,6 is considered to be $196 \mathrm{~J} / \mathrm{g}$ [26].

Furthermore, in order to study the dispersion state and other possible involved mechanisms in the behavior of the nanocomposites produced via different methods, scanning electron microscopy (SEM) (Quanta FEG 200 ESEM) was employed on the fractured surfaces of the nanocomposites using a charging method. In addition, transmission electron microscopy (TEM) (FEI Tecnai ${ }^{\mathrm{TM}} \mathrm{G}^{2}$ 20) was used on the ultramicrotomed (Leica Ultracut UCT, Leica Microsystems, Germany) films with $70 \mathrm{~nm}$ thickness in order to study the orientation and arrangement of the nanofillers within the polymeric system.

Melt rheological properties of the nano- and hybrid- composites were acquired from experiments conducted in a Discovery HR-2 (TA Instruments, USA). In order to prepare the $25 \mathrm{~mm}$ disc-shape samples, granulates of nanocomposites were compression molded between the preheated plates for $6 \mathrm{~min}$. Subsequently, the oscillatory shear measurements were performed in nitrogen atmosphere with $1.0 \mathrm{~mm}$ gap between the plates. Each experiment was conducted on the three different specimens prepared from each batch using strains within the linear viscoelastic range, which had already been defined using strain amplitude sweeps.

\section{Results and discussion}

\subsection{Single nanofiller inclusion}

In order to understand how the single inclusion of the introduced nanofillers in the composites influences the properties of the nanocomposites, PA 6,6 based nanocomposites comprising different contents of either MWCNTs or GNPs were produced and studied [7]. In Figure 2 the results for elastic modulus (Fig. 2(a)), tensile strength (Fig. 2(b)), Hardness (Fig. 2(c)), and thermal conductivity (Fig. 2(d)) are shown. Results show that incorporation 
of either of the nanofillers in the polymeric matrix increases the elastic moduli consistently. In fact, addition of the $6.0 \mathrm{wt}$. \% nanofillers in the nanocomposites lead to 45 and $41 \%$ increase in the elastic moduli of the nanocomposites containing GNPs and MWCNTs, respectively. In contrast to stiffness, tensile strengths of the nanocomposites reinforced with MWCNTs were higher for all the investigated nanofiller contents. It is also noteworthy to mention that for both nanocomposite types, contents higher than $3.0 \mathrm{wt}$. \% nanofiller inclusion resulted into lower tensile strengths indicating larger agglomeration sites and/or less control on the alignment along the flow. Similar to elastic moduli, the hardness values increased consistently while adding more nanofillers within the polymeric matrix (Fig. 2(c)). This constant improvement resulted into 36 and $25 \%$ enhancement of hardness values in the nanocomposites containing 6.0 wt. \% g GNPs, and MWCNTs, respectively.
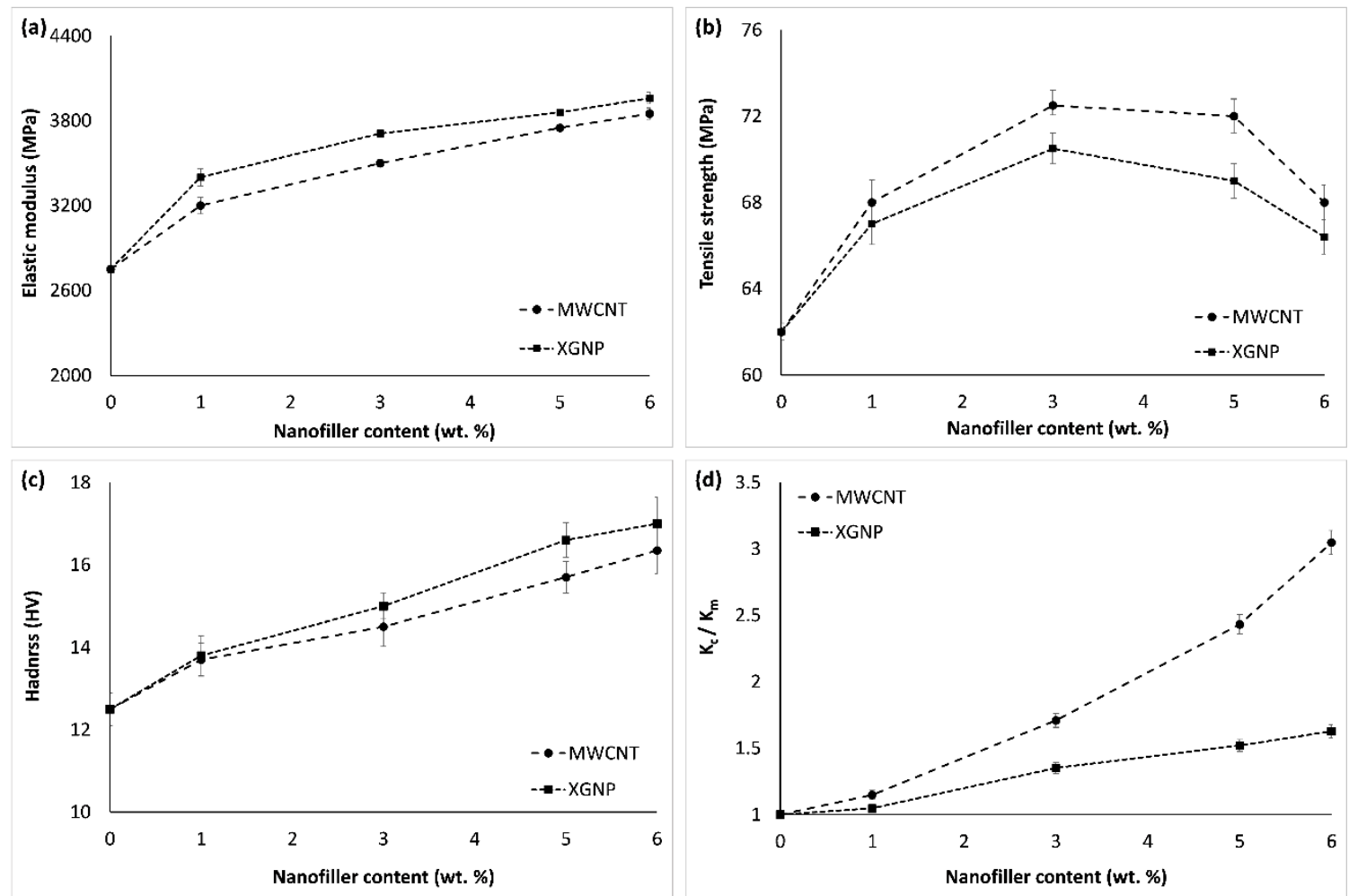

Fig. 2 Influence of the nanofillers content on the (a) elastic modulus, (b) tensile strength, (c) hardness, and (d) thermal conductivity of the produced nanocomposites. ( $K_{C}$ and $K_{m}$ are the thermal conductivities of the nanocomposites and matrix, respectively). 
Moreover, the thermal conductivity of the produced nanocomposites was also studied. Fig. 2(d) shows the normalized enhancement of the thermal conductivities with respect to the thermal conductivity of the neat PA 6,6. As it can be noticed from the curves, the thermal conductivity is increasing with the nanofiller content, and the rate of enhancement is more pronounced for specimens containing carbon nanotubes. In fact, while the nanocomposites containing 6.0 wt. \% carbon nanotubes are showing three times improvement in the thermal conductivities, the nanocomposites containing similar contents of graphene present nearly half of this value.

Fig. 3 shows the crystallinity in the polymeric matrix depending on nanofiller content within the nanocomposite systems. Results show that carbon nanotubes are acting as a stronger nucleating agents compared to the Graphene NanoPlatelets. However, increasing the content of the nanotubes more than $3.0 \mathrm{wt}$. \% is reversing this increasing trend. In fact, with higher contents of the tubes, polymer chains do not have the same freedom to rearrange into a crystalline structure effectively. This confinement hinders additional crystallization. The similar behavior is also observed in other studies [7], [27], [28]. In contrast, in the nanocomposites reinforced with GNPs, the increasing trend is continuing even in the higher contents. This constant improvement indicated that the similar confinement influence of the nanotubes was not present in the nanocomposites reinforced with GNPs. The following rheological and electron microscopy investigation reveals the difference in the constructed network of the nanofillers in the produced specimens.

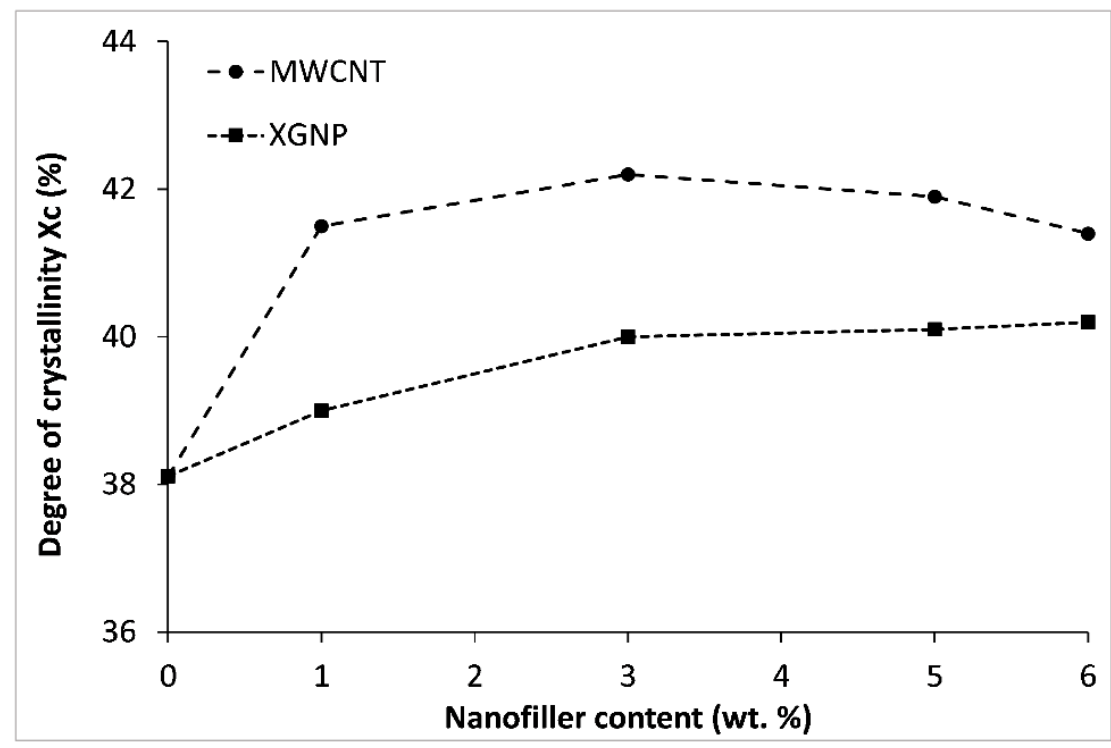


Fig. 3 Influence of nanofiller contents on the degrees of crystallinity of the produced nanocomposites.

\subsection{Interaction between the two nanofillers}

Following the investigation of the nanocomposites containing one type of nanofillers, hybrid nanocomposites containing both MWCNTs and GNPs were produced and investigated with the motivation being to investigate whether simultaneous presence of the nanofillers can lead into improved dispersion and other properties or not.

The processing behavior of the prepared batches of nano- and hybrid-composites is firstly studied. The method of production in this study, and also in many other plastic composite productions is injection and compression molding. Therefore, the melt behavior plays a crucial role in their processing. Injection and compression molding usually employ a shear rate higher than $20 \mathrm{~s}^{-1}$ and $1 \mathrm{~s}^{-1}$ during manufacturing, respectively [29]. Fig. 4 illustrates the rheological behavior of the nano- and hybrid- composites containing 3.0 and $6.0 \mathrm{wt}$. \% nanofillers. As it can be noticed from the curves, the viscosity, the storage and loss moduli increase significantly with the addition of the content of the nanofillers in the polymer matrix. Moreover, the nanocomposites containing carbon nanotubes showed significantly higher viscosities and moduli compared to the nano- and hybrid- composites containing GNPs in the similar nanofiller contents. In all of the studied nanocomposites, the Newtonian plateau was not present, and only the shear thinning defined the melt behavior, while the viscosity decreases constantly with the increase of the frequencies.

Furthermore, it should be noted that in all of the produced composites containing carbon nanotubes, the damping parameters ( $\tan \delta=G^{\prime \prime} / G^{\prime}$ ) through the whole span of the studied frequencies were less than one. This behavior indicates the dominance of a solid-like behavior of the melt. However, the introduced damping parameter in the nanocomposites containing just GNPs became more than one in the frequencies higher than $10 \mathrm{rad} / \mathrm{s}$, indicating more liquid-like behavior in higher shear rates.

Moreover, it should be noted that as more nanotubes are present in the system, both moduli especially storage moduli became more independent of the applied frequencies. In fact, the slope of the increase of the storage moduli as the function of applied frequencies reduced at higher contents of the nanotubes in the system. This behavior indicates the existence of an interconnected network of the fillers [30]. Results show that the increase in the content of the nanofillers in the hybrid nanocomposites lead to additional interaction and connectivity between the nanofillers within the polymeric melt. 

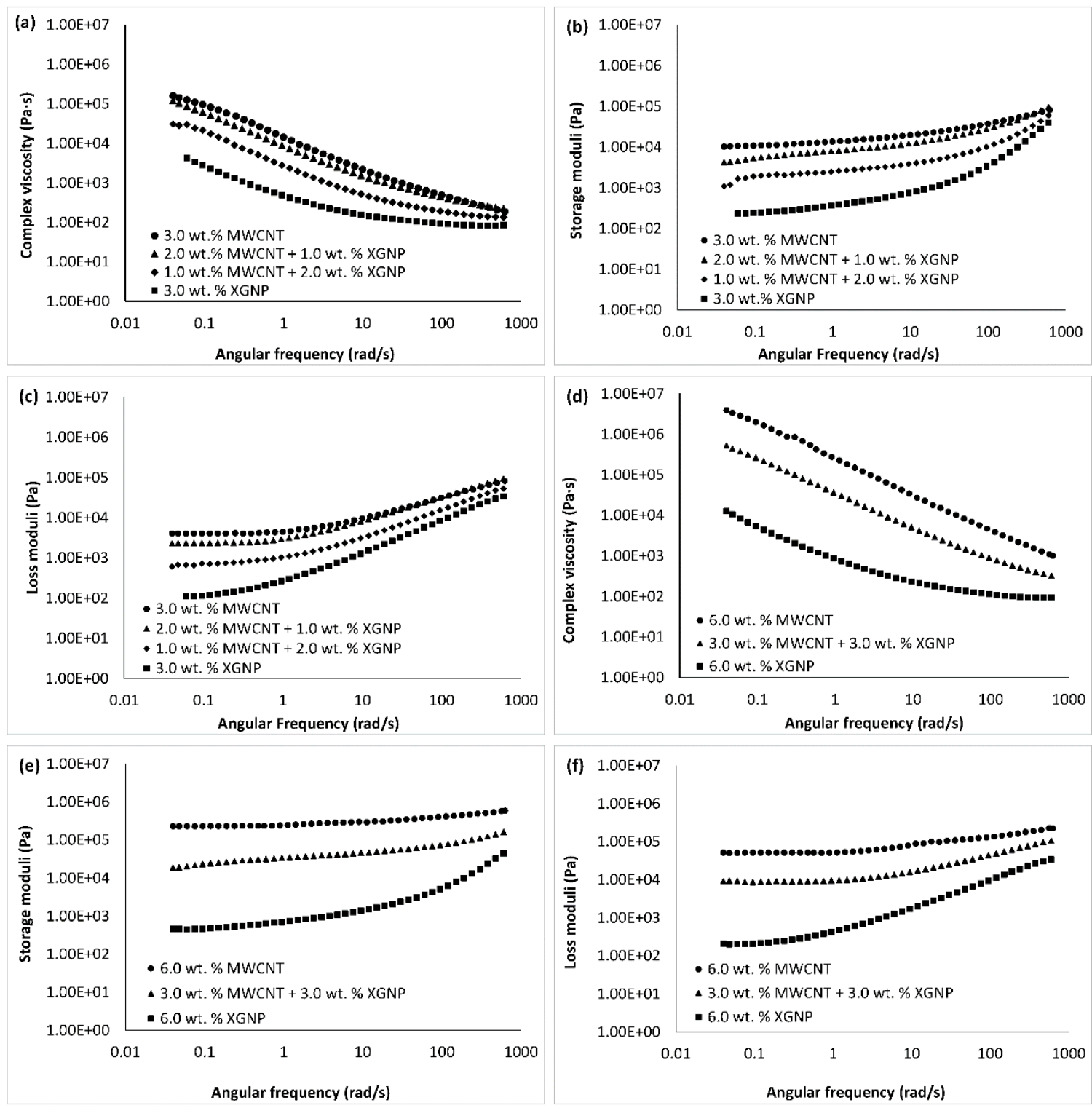

Fig. 4 The rheological parameters of the nano- and hybrid- composite melts containing (a)(c) 3.0 wt. \%, and (d)-(f) 6.0 wt. \% of the nanofillers.

Fig. 5 shows the comparison between the 3.0 wt. \% nanofiller reinforced composites containing different mixture ratios of the nanofillers. Results show that replacing $1.0 \mathrm{wt}$. \% carbon nanotubes with Graphene NanoPlatelets lead to notable increase in the 
mechanical properties compared to the nanocomposites containing $3.0 \mathrm{wt}$ \% of only MWCNTs or GNPs. In fact, elastic moduli, tensile strengths, and hardness values increased in the hybrid nanocomposites. However, replacing 1.0 wt. \% Graphene NanoPlatelets with carbon nanotubes decreased the tensile strength values. It seems that when the nanocomposite system is dominated by the carbon nanotubes, the system can benefit from the addition of the second nanofiller effectively. However, the trend in thermal properties was different, where the nanocomposites containing MWCNTs were showing higher thermal conductivities, and addition of the second nanofiller did not improve the conductivities additionally.
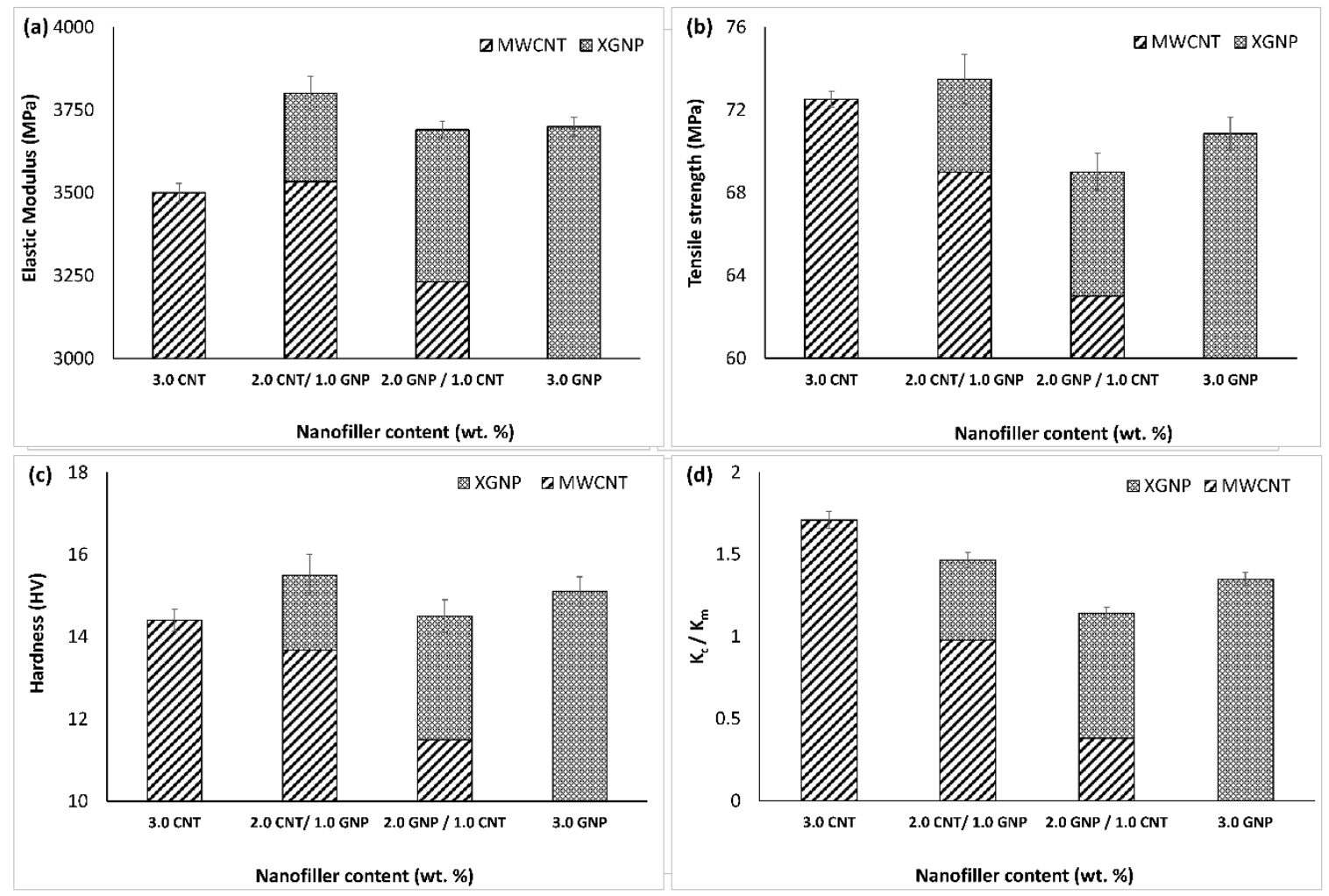

Fig. 5 Comparison of (a) Elastic moduli, (b) tensile strengths, (c) hardness values, and (d) thermal conductivities between the nanocomposites containing $3.0 \mathrm{wt}$. \% varying ratios of the nanofillers.

TEM micrographs (Fig. 6) show the microstructure within the injection molded nano and hybrid composites. In fact, thinner polymer layers around the surface of the nanofillers 
and the higher contact area between the nanofillers and the polymer (larger interface area) enhance the phonon transport [31]. Therefore, increasing the content of the nanofillers while having a proper dispersion state (reduced size and number of agglomerations) should enhance the thermal conductivities. Fig. 6 (a) and (b) show the arrangement of the nanofillers in the nanocomposites containing similar contents of the fillers. As a networkshape arrangement of nanotubes can be noticed from the micrographs, the minimum distances between the carbon nanotubes is less than the ones in the nanocomposites reinforced with GNPs. As a result, one can expect higher thermal conductivity in the nanocomposites containing MWCNTs. Fig 6 (c) and (d) also show the state of the nanofillers in the hybrid nanocomposite containing 2.0/ $1.0 \mathrm{wt}$. \% MWCNTs/GNPs. The graphs in addition of presenting a proper de-agglomeration indicate the dominance of the carbon nanotubes in the composite system. 

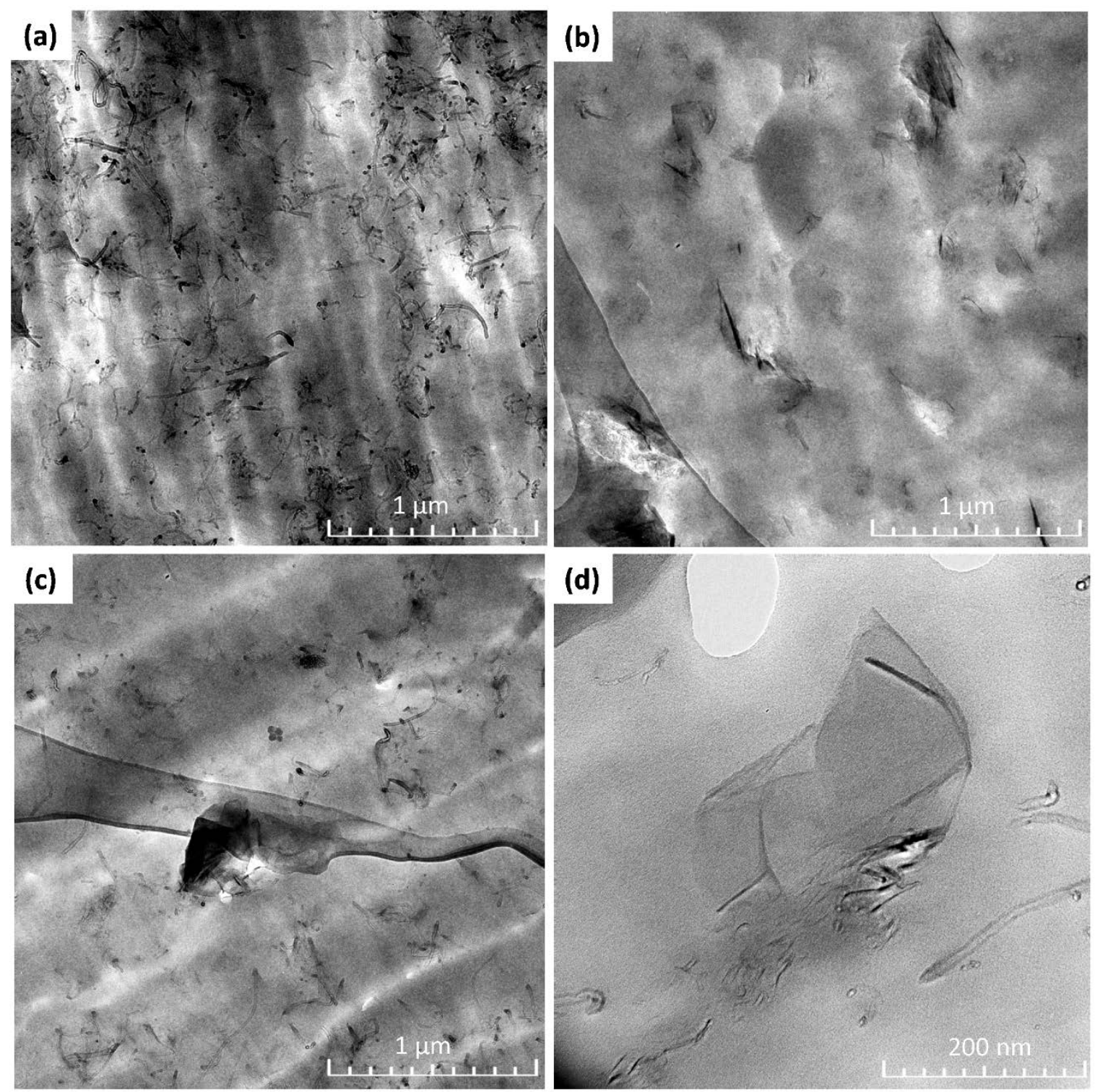

Fig. 6 TEM micrographs of the microstructure in the nanocomposites reinforced with (a) 6.0 wt. \%MWCNTs, (b) 6.0 wt. \% GNPs, and (c) both of the nanofillers. (d) Higher magnification of the vicinity of the both nanofillers in the hybrid nanocomposites.

Table 1. presents the crystallization and melting characteristics of the composites containing $3.0 \mathrm{wt}$. \% nanofillers. The highest degree of crystallinity was observed in the hybrid nanocomposites containing 2.0/1.0 wt. \%MWCNTs/GNPs. It should be also noted 
that the addition of carbon nanotubes shifted the behavior towards the nanocomposites containing 3.0 wt. \% MWCNTs. In fact, nearly similar temperatures and degrees of crystallinity were observed in all the composites containing any content of carbon nanotubes.

Table 1. Comparison of the nonisothermal crystallization and melting parameters of the nanocomposites containing 3.0 wt. \% nanofillers acquired from the DSC curves.

\begin{tabular}{|c|c|c|c|}
\hline $\begin{array}{c}\text { Nanocomposite } \\
\text { Specimen } \\
\text { content }\end{array}$ & $\begin{array}{c}\text { Crystallization } \\
\text { temperature } T_{C}\left({ }^{\circ} \mathrm{C}\right)\end{array}$ & $\begin{array}{c}\text { Melting } \\
\text { temperature } T_{M} \\
\left({ }^{\circ} \mathrm{C}\right)\end{array}$ & $\begin{array}{c}\text { Degree of } \\
\text { crystallinity } \mathrm{X}_{\mathrm{C}} \\
(\%)\end{array}$ \\
\hline PA 6,6 neat & 235.6 & 238.8 & 38.1 \\
\hline $\begin{array}{l}3.0 \text { wt. } \% \\
\text { MWCNT }\end{array}$ & 244.3 & 260.6 & 42.2 \\
\hline $\begin{array}{l}2.0 \text { wt. \% } \\
\text { MWCNT + } 1.0 \\
\text { wt. \% GNP }\end{array}$ & 244.8 & 261.1 & 42.3 \\
\hline $\begin{array}{l}1.0 \text { wt. } \% \\
\text { MWCNT + } 2.0 \\
\text { wt. \% GNP }\end{array}$ & 243.5 & 260.9 & 42.1 \\
\hline 3.0 wt. \% GNP & 242.9 & 259.1 & 40.0 \\
\hline \multicolumn{4}{|c|}{$\begin{array}{l}\text { In order to understand the interaction between the two nanofillers within the polymeric } \\
\text { natrix better, nanocomposites containing } 6.0 \mathrm{wt} \text {. \% of the nanofillers were also studied } \\
\text { see Fig. 7). Similar to the nanocomposites containing } 3.0 \mathrm{wt} \text {. \% nanofillers, the elastic } \\
\text { nodulus increased with introducing the second nanofiller in the nanocomposite system. } \\
\text { However, the resulted tensile strength was less than both of the nanocomposites filled with } \\
\text { ust one type of the nanofillers. It seems that inclusion of higher contents of Graphene in } \\
\text { he polymeric matrix aggravates the dispersion state of the composite system, which leads } \\
\text { o larger agglomeration and less tensile strengths. SEM images in Fig. } 8 \text { are showing the } \\
\text { lispersion states in the nanocomposites containing } 6.0 \mathrm{wt} \text {. \% MWCNTs and the hybrid } \\
\text { lanocomposites containing } 3.0 / 3.0 \mathrm{wt} \text { \% MWCNTs/GNPs. In fact, more agglomerations } \\
\text { rom both of the nanofillers were observed in the structure of the hybrid composites. }\end{array}$} \\
\hline
\end{tabular}



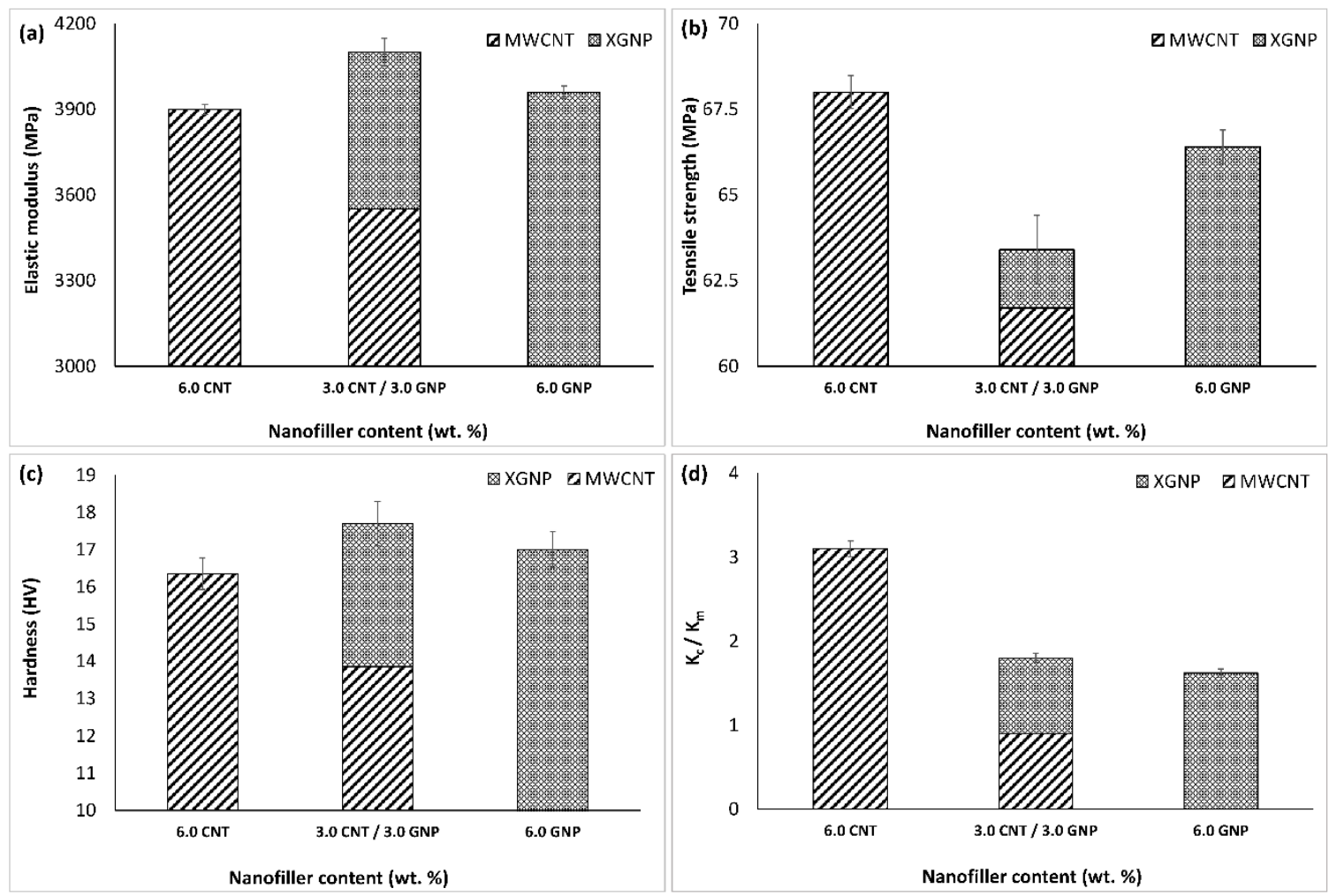

Fig. 7 Comparison of (a) Elastic moduli, (b) tensile strengths, (c) hardness values, and (d) thermal conductivities between the nanocomposites containing $6.0 \mathrm{wt}$. \% nanofillers with varying ratios.

Thermal conductivities were also showing the previously observed trend, where the nanocomposites containing MWCNTs present better thermal conductivities compared to the other prepared specimens. It seems that the increased size and number of agglomerations lead to more scattering of phonons. Therefore, increase in the conductivities compared to the nanocomposites containing only GNPs was not observed. 

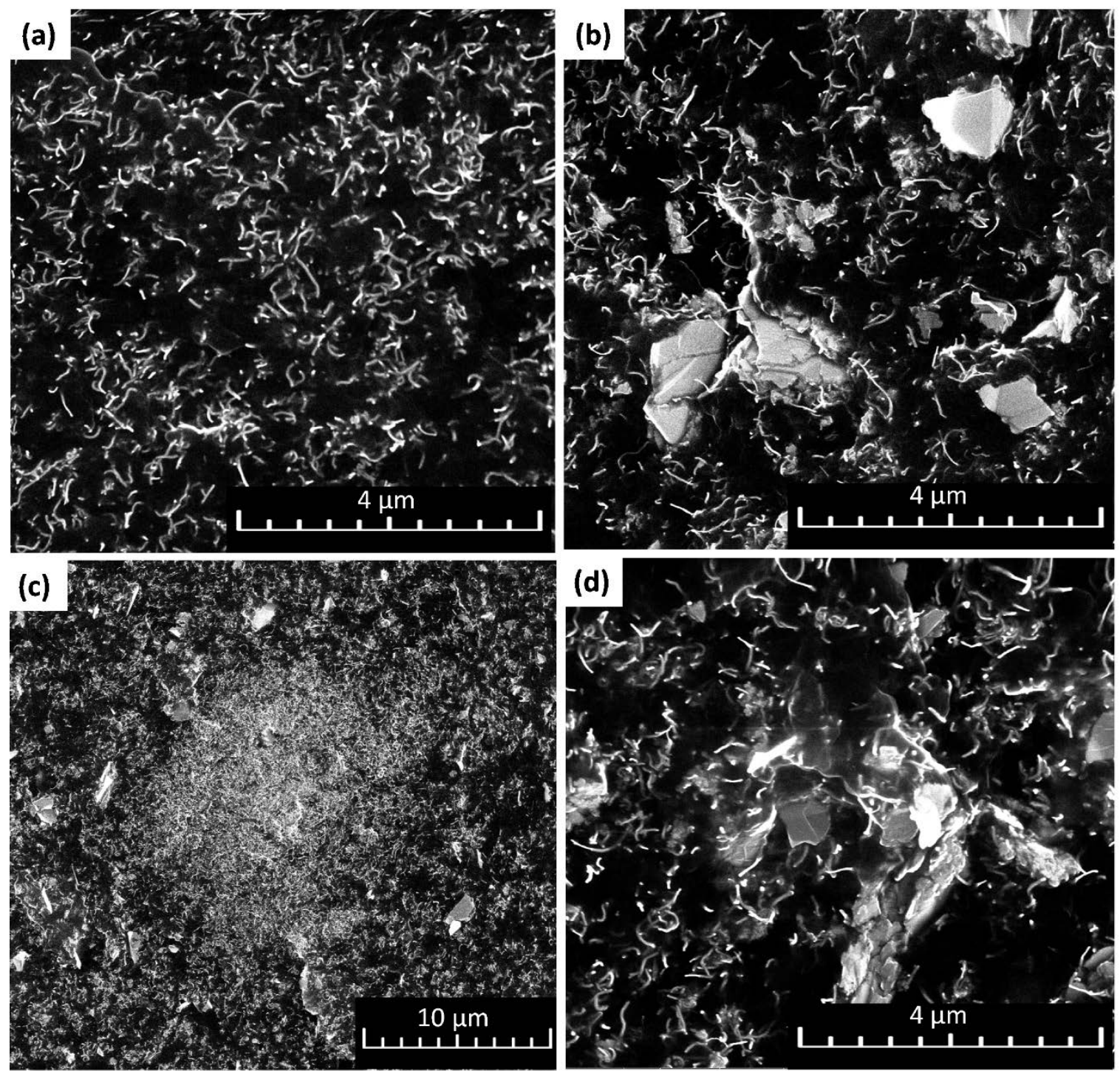

Fig. 8 Dispersion state in the nanocomposites containing (a) MWCNTs and (b) both MWCNTs and GNPs. Representative of the (c) MWCNT and (d) GNP agglomerated phase in the hybrid nanocomposites. 


\section{Conclusions}

PA 6,6 based hybrid- and nano- composites containing different contents of carbon nanotubes and Graphene NanoPlatelets were produced via melt mixing and injection molding. Results showed that combination of nanofillers lead to additional improvement of the mechanical properties compared to the nanocomposites containing either of the nanofillers especially in the lower nanofiller contents. In fact, while inclusion of the smaller percentage of the GNPs within the MWCNTs reinforced composites improved the mechanical properties, adding more amounts of the graphene nanofillers did not enhance the properties. Moreover, crystallization and rheological studies revealed the dominant influence of the nanotubes in the hybrid nanocomposites. Even smaller amounts of the carbon nanotubes in the hybrid systems shifted the degrees of crystallinity and viscosities toward the nanocomposites containing only MWCNTs. It is assumed that addition of the smaller amount of the of graphene nanofillers is favorable to the dispersion state. Moreover, they might have protected nanotubes against shortening and damage resulting from the applied shear stress during processing. However, addition of more amounts of the Graphene nanofillers induced more nanofiller agglomerations in the system. The constructed network of the nanotubes and the reduced average distance between the fillers also resulted into better thermal conductivities in higher contents of the nanotubes. The investigated microstructure and dispersion states from scanning and transmission electron microscopies also revealed how the nanofillers are positioning themselves in the hybrid nanocomposite systems.

\section{Acknowledgements}

Authors would like to thank Dr. Sabine Schlabach for her assistance in TEM sample preparation, which carried out with the support of the Karlsruhe Nano Micro Facility (KNMF, www.kit.edu/knmf), a Helmholtz Research Infrastructure at Karlsruhe Institute of Technology (KIT, www.kit.edu ).

\section{References}

[1] Kim P, Shi L, Majumdar A, McEuen PL. Phys. Rev. Lett. 2001, 87, 215502.

[2] Hone J, Whitney M, Piskoti C, Zettl A. Phys. Rev. B 1999, 59, R2514.

[3] Meyyappan M. Carbon Nanotubes: Science and Applications, CRC Press2004.

[4] Thostenson E, Li C, Chou T. Compos. Sci. Technol. 2005, 65, 491-516. 
[5] Ayatollahi MR, Doagou-Rad S, Shadlou S. Macromol. Mater. Eng. 2012, 297, 689-701.

[6] Alishahi E, Shadlou S, Doagou-R S, Ayatollahi MR. Macromol. Mater. Eng. 2013, 298.

[7] Doagou-Rad S, Islam A, Jensen JS. J. Compos. Mater. 2018, 52, 3681-3697 .

[8] Doagou-Rad S, Islam A, Jensen JS. Procedia CIRP 2017, 66, 131-136.

[9] Sumfleth J, Adroher XC, Schulte K. J. Mater. Sci. 2009, 44, 3241.

[10] Al-Saleh MH. Synth. Met. 2015, 209, 41-46.

[11] Ren P, Di Y, Zhang Q, Li L, Pang H, Li Z. Macromol. Mater. Eng. 2012, 297, 437-443.

[12] Reddy KR, Sin BC, Ryu KS, Kim J-C, Chung H, Lee Y. Synth. Met. 2009, 159, 595-603.

[13] Yang K, Gu M. Compos. Part A Appl. Sci. Manuf. 2010, 41, 215-221.

[14] Aiping Y, Palanisamy R, Xiaobo S, Elena B, E. IM, C HR. Adv. Mater. 2008, 20, 4740-4744.

[15] Hou Y, Cheng Y, Hobson T, Liu J. Nano Lett. 2010, 10, 2727-2733.

[16] Teng C-C, Ma C-CM, Chiou K-C, Lee T-M, Shih Y-F. Mater. Chem. Phys. 2011, 126, 722-728.

[17] Li W, Dichiara A, Bai J. Compos. Sci. Technol. 2013, 74, 221-227.

[18] Chatterjee S, Nafezarefi F, Tai NH, Schlagenhauf L, Nüesch FA, Chu BTT. Carbon N. Y. 2012, 50, 5380-5386.

[19] Zhang S, Yin S, Rong C, Huo P, Jiang Z, Wang G. Eur. Polym. J. 2013, 49, 3125-3134.

[20] Kumar S, Sun LL, Caceres S, Li B, Wood W, Perugini A, Maguire RG, Zhong WH. Nanotechnology 2010, 21, 105702.

[21] Mayoral B, Garrett G, McNally T. Macromol. Mater. Eng. 2014, 299, 748-756.

[22] Hamaker HC. Physica 1937, 4, 1058-1072.

[23] Tomas J, Kleinschmidt S. Chem. Eng. Technol. 2009, 32, 1470.

[24] Rumpf H. in Agglomeration (Ed: W. Knepper), Interscience Publishers, New York 1962, 379.

[25] Rwei SP, Manas-Zloczower I, Feke DL. Polym. Eng. Sci. 1990, 30, 701-706.

[26] Brandrup J, Immergut EH, Grulke EA, Abe A, Bloch DR. Polymer Handbook, John Wiley \& Sons, Inc., New York 1989.

[27] Logakis E, Pandis C, Peoglos V, Pissis P, Stergiou C, Pionteck J, Pötschke P, Mičušík M, Omastová M. J. Polym. Sci. Part B Polym. Phys. 2009, 47, 764-774.

[28] Jiang Z, Hornsby P, McCool R, Murphy A. J. Appl. Polym. Sci. 2012, 123, 26762683.

[29] Chiu Y-C, Huang C-L, Wang C. Compos. Sci. Technol. 2016, 134, 153-160.

[30] Pötschke P, Fornes TD, Paul DR. Polymer. 2002, 43, 3247-3255.

[31] Yang S-Y, Ma C-CM, Teng C-C, Huang Y-W, Liao S-H, Huang Y-L, Tien H-W, 
Lee T-M, Chiou K-C. Carbon N. Y. 2010, 48, 592-603. 